\title{
Traduire
}

Une autre perspective sur r tr traduction

Revue française de la traduction

$221 \mid 2009$

Voies de l'interprétation

\section{Marguerite : Oh Seigneur, j'avais les blues !}

\section{Christian Casoni}

\section{OpenEdition}

\section{Journals}

Édition électronique

URL : http://journals.openedition.org/traduire/353

DOI : 10.4000/traduire.353

ISSN : 2272-9992

\section{Éditeur}

Société française des traducteurs

\section{Édition imprimée}

Date de publication : 15 décembre 2009

Pagination : 112-115

ISSN : 0395-773X

\section{Référence électronique}

Christian Casoni, « Marguerite : Oh Seigneur, j'avais les blues! », Traduire [En ligne], 221 | 2009, mis en ligne le 12 novembre 2013, consulté le 25 novembre 2020. URL : http://journals.openedition.org/ traduire/353 ; DOI : https://doi.org/10.4000/traduire.353 


\section{Compte rendu d'ouvrage \\ Marguerite \\ Oh Seigneur, j'avais les blues !}

\section{Christian Casoni}

J'ai écouté quelques-unes de ces musiques de percussion ou de guitare, produites souvent aussi par n'importe quoi, le raclement d'un couteau, le grincement d'une fiole de verre, le bruit d'une poignée de porte battant contre un mur, l'effet rythmique étourdissant d'un rasoir contre une courroie de cuir : tout est bon pour faire sortir des choses la musique qui est en elles.

\section{Un ruban, une épée}

Marguerite de Crayencour, née Bruxelloise en 1903, plus connue sous l'anagramme de Yourcenar, avait vraiment tout pour nous plaire, depuis son exil volontaire aux États-Unis en 1937 avec la femme de sa vie, Grace Frick, au dernier ouvrage qu'elle publia : Blues et Gospels.

Lorsqu'elle fit paraître ce choix de traductions, Marguerite Yourcenar était déjà académicienne française, élevée au grade de commandeur de la Légion d'honneur. Qu'un(e) auteur(e) à ce point bernard-pivotée, jacques-chancélisée, ayant sacrifié comme il fallait aux vanités de sa profession et rompue aux mondanités des cercles littéraires, s'encanaille en bout de course avec Bessie Smith et Leadbelly, voilà de quoi corrompre nos pitoyables certitudes underground !

Mais en 1984, lorsque paraît Blues et Gospels, l'académicienne ne courtise pas en ingénue les mânes de la musique noire américaine. En 1939 déjà, alors qu'un orage terrible gronde sur l'Europe, elle sillonne les États du Deep South et, dès 1955, milite en faveur des Droits civiques. Ratte de bibliothèque "en quête des textes les plus anciens et les moins retouchés", elle publie une première sélection de chants gospels en 1964 : Fleuve profond, sombre rivière.

Durant ses pérégrinations américaines, elle éprouve " cette gentillesse particulière aux gens de couleur dès qu'ils flairent la sympathie et non la condescendance ". Elle connaît bien ces " petites villes de Blancs, $[\ldots]$ braves gens cordiaux, [...] en qui néanmoins repose une lie de préjugés et de méfiances raciales et sociales, dépôt dangereux qu'on trouve partout dans ce qu'on appelle l'âme humaine. Çà et là flambent encore parfois les croix de feu du Klan - ce groupe n'a rien perdu de sa redoutable vitalité. " 


\section{Quatorze + quatorze}

Lorsque le cancer lui arrache Grace Frick en 1979, Marguerite termine platoniquement cette idylle avec Jerry Wilson, un jeune réalisateur " né et grandi sur l'une des immenses fermes du Sud à l'époque, si récente encore, où les femmes des ouvriers noirs emmenaient l'enfant blanc pêcher dans la rivière le poisson-chat. "Homosexuel, Jerry meurt du sida à trente ans.

L'objet de la quête de Jerry Wilson est les gospels (...) et les blues, grand art vite évaporé comme tout art populaire, complaintes ou chansons qui, parties de boites de nuit pauvres ou des vérandas branlantes des métairies misérables, se sont répandues sur le monde, souvent déformées ou dénaturées.

Un an avant la sortie de Blues et Gospels, Marguerite Yourcenar et Jerry Wilson parcourent l'Arkansas. Jerry tourne pour la télé le documentaire Saturday Blues. On y entend la voix de Marguerite commenter les images.

Un an plus tard, l'académicienne légionnaire choisit quatorze blues et quatorze gospels (pourquoi quatorze ?) ; elle en traduit les textes comme si elle s'attaquait à des poésies réalistes.

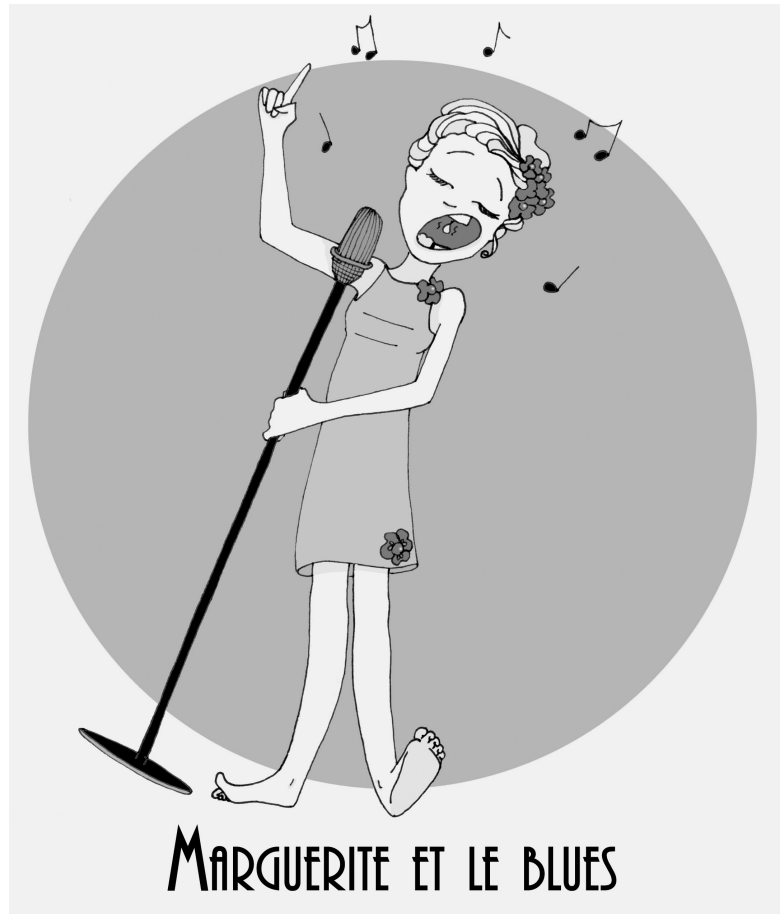

Illustration : Marlène Junius, http://alotoftralala.over-blog.com 
Gallimard scinde le corpus en deux recueils distincts, un cahier blues, un cahier gospels, et les place comme des parenthèses autour d'un album de photos signé Jerry Wilson.

Les images sont très belles et montrent des scènes et des portraits qu'on s'attend à trouver dans un ouvrage consacré au blues et au gospel : le travail dans les champs de coton, les devantures colorées des juke-joints, des visages d'enfants, des vieillards ridés comme des cartes d'état-major, des mariages graves et, pour finir, quelques cercueils et un cimetière.

Marguerite, elle, ne nous dit jamais rien. Taupe rêveuse, elle creuse sa galerie d'un bout à l'autre du livre, détachée des messages terribles qu'elle laisse dans son sillage ("Elle l'avait étripé, elle l'avait bel et bien saigné ॥). Elle accorde blues au pluriel, comme une vieille blueswoman et, plus curieux, assigne à ce mot le genre féminin... comme si elle parlait des amours. "Et tôt c'matin, les blues sont entrées dans ma chambre. "Bourgeois Blues est ainsi traduit : Les blues bourgeoises!

Marguerite ne flèche pas sa promenade. II faut deviner que Monsieur Samuel, c'est le Ticket Agent Blues de Blind Willie McTell, que Ma Douce vient du Walking Blues (crédité Bill Wilber), ou que Les blues de la Prohibition ne sont autres que Me And My Gin de Bessie Smith. La vieille dame traverse l'album de Jerry Wilson, aveugle aux images, ne se souciant pas de leur trouver l'alibi d'une légende... et sort de terre dans une apothéose de gospels, chœurs d'espoir et de liberté ("Ils l'ont fouetté, toute la nuit, ils l'ont fouetté toute la nuit pour moi "). Cette évasion de la galerie vers l'air libre, d'autres avant elle l'avaient appelée Germinal.

\section{La scierie brûle}

Marguerite adopte, pour ses traductions, des clauses de style pas rock'n'roll pour un sou, leur apporte le charme cocasse d'une gouaille d'affranchie à laquelle on a du mal à croire, prête à l'expression noire la candeur un peu risible d'un polar français des années 50. "L'jour de la paie l'un d'ces jours, pour tous ceuss' qui travaillent ici, pour tous ceuss' qui se sont privés, et traînent une croix d'un poids très lourd " (Révérend W. Herbert Brewster). "Oh, faites mon plein d'bon vieux gin, vous verrez qu'je s'rai une gentille copine " (Bessie Smith). "Et les Blancs, à Washington, on peut dire qu'ils savent y faire, prendr' un sou, et l'jeter à un nègr' pour l'voir se baisser jusqu'à terre " (Leadbelly).

Mais Marguerite n'a plus rien à démontrer ni aucune justification à fournir. Grace Frick est morte, Jerry Wilson est malade. Comme dans la chanson de Sam Ligthnin' Hopkins, un enfant bègue la met en garde : La scie-rie brûle. Elle, par la voix de "Monsieur Charlie " : "Mets la tête dehors et regarde-la brûler !".

Le blues, c'est une chose d'en écouter. C'en est une autre de se sentir visé. 
Blues et Gospels, recueil de textes traduits et présentés par Marguerite Yourcenar, illustré de photographies de Jerry Wilson, Gallimard, 1984.

Christian Casoni est rédacteur en chef de Blues Again !, magazine culturel abordant le blues sous son aspect musical, social et politique; base des musiques du xxe siècle, ne vous étonnez pas d'entendre parler ici de gospel, de jazz, de rock'n'roll, de soul, de rock ou de ses racines africaines :

http://www.bluesagain.com/index.htm/

L'article offert à la revue "Traduire " est extrait du numéro 9, publié au printemps 2007-rubrique Wang Dang Doodle.

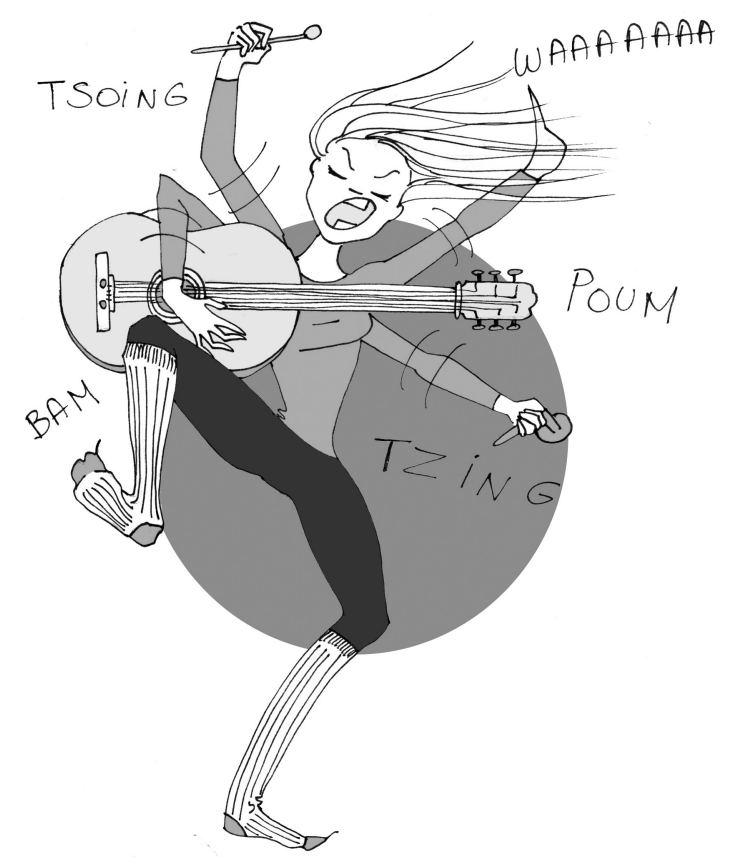

Illustration : Marlène Junius, http://alotoftralala.over-blog.com 